\title{
Enlightenment on Modern Urban Planning of the Traditional Construction Wisdom in Lingnan Region
}

FENGYAN LI, South China University of Technology,China

QI LU,South China University of Technology, China

\begin{abstract}
This paper explores how the traditional construction wisdom of Lingnan region deals with urban planning to gain better human comfort. The traditional construction wisdom of Lingnan region adopts unique design techniques such as layout, ventilation and heat insulation, which not only adapts to the hot and humid summer climate in southern China, but also realizes the effect of "natural air conditioning" in urban planning. The traditional construction wisdom has a history of thousands of years and are the quintessence of the wisdom of Chinese traditional culture. This author makes a field measurement of the thermal environment in Donghuali community, Foshan city (in Guangdong province, $P R C$ ), extracting such the thermophysical parameters as air velocity, wind direction, temperature, relative humidity, and conducting an analysis of human comfort, to discuss through the data how the traditional construction wisdom of Lingnan works. The paper focuses on whether the traditional wisdom can be tested in a scientific way, and what kind of design inspiration it brings to contemporary urban planning.

The breakout of COVID-19 is not only a test for all mankind, but also a reflection on urban planning. In the post-coronavirus era, urban planning should not only stay in the temporary state of simply preventing the recurrence of the epidemic. The potential risks that blocks, communities and cities may face should be analyzed more systematically to comprehensively improve the sustainable development of the building. The conclusion of this paper is that the traditional construction wisdom of Lingnan region can effectively solve the problem of hot and humid climate in summer in southern China without active energy sources assistance, better meet the requirements of human comfort, and play a positive role in the sustainable development of urban planning in the post-epidemic era.
\end{abstract}

\section{Keywords}

Construction Wisdom, Measurement of Thermal Environment, Urban Planning, Human Comfort Evaluation

\section{INTRODUCTION}

In the context of global energy shortage and the post-COVID19 time, building energy conservation, comfort level, and health concern have attracted more attention in public. Tracing back to thousands of years ago, with their outstanding wisdom, our ancestors had built a huge number of low-energy consumption buildings suitable for human living in a health lifestyle.These traditional construction techniques have a history of thousands of years and are the quintessence of the wisdom of Chinese traditional culture. Located in southern China, Lingnan belongs to the humid subtropical hot climate. In summer the temperature is quite high with a long duration. The relative humidity is also high. The solar radiation intensity is high, and the sunshine lasts for a long time.The traditional urban planning in Lingnan area has addressed the issue of "natural air-conditioning" effect of the community environment and adapts to the humid and hot summer climate in southern China by adopting unique street layout, building ventilation, building thermal insulation, and other design measures, as well as the "climate space" planning pattern.It enjoys its unique advantages in improving indoor and outdoor thermal comfort 
compared with modern urban planning technologies. Many scholars at both home and abroad have done much research on them(Fan et al., 2009, Allard et al., 1998, 2000, Zhao and Hui, 2005).However, the research on the thermal environment of traditional architectures concentrated greatly on qualitative analysis, numerical simulation and model test research, lacking research on field test.This paper is focused on investigating the formation mechanism of Lingnan traditional building construction in intelligently solving urban thermal environment problems, and exploring reasons for meeting the requirements of human body comfort evaluation, thereby providing enlightenment for contemporary urban planning.

\section{METHODS}

WELL Standard (US) and BREEAM standard (UK) are the most authoritative international healthy building standards at present, both setting respective requirements for a healthy thermal environment. Referring to above standards, "Evaluation standard for indoor thermal environment in civil buildings" in China adopts APMV as an indicator to determine the qualification of more than $90 \%$ of the rooms. Furthermore, for class III evaluation, no marks will be added, indicating that under natural ventilation, class I is the best, followed by class II, and class III urgently needs the improvement of the indoor thermal environment[5].This author makes a field measurement of the thermal environment in Donghuali community, Foshan City, extracting such the thermophysical parameters as air velocity, wind direction, temperature, relative humidity, and carrying on the PMV, to discuss through the data how the traditional construction wisdom of Lingnan works.

\subsection{Field Test}

Located in the south-central part of Guangdong Province, China, Foshan City is the core of the Pearl River Delta and one of the four famous towns in ancient China. In the research object of Donghuali community, an old city center of Foshan, over 50 ancient residences of the Qing Dynasty are preserved here, mainly characterized by the typical "three rooms and two corridors". With a history of more than 300 years, the street pattern and residential buildings still retain the traditional form. In 2001, the community was rated as a national cultural relics protection unit(Fig.1).The annual highest temperature in the whole community is $38.1^{\circ} \mathrm{C}$, the lowest is $4^{\circ} \mathrm{C}$, and the annual average temperature is $22.1^{\circ} \mathrm{C}(\mathrm{Li}$ et al.,2021). The author team conducted a field test on Donghuali community in July 2020. Three sets of measuring points were set up indoors and outdoors(Fig.2). Measuring point 1 was set in main streets, point 2 in front of a residence, point 3 in the roadway, point 4 in the indoor patio, point 5 in the hall, and point 6 in a room. The temperature and humidity collector automatically recorded every 5 minutes with the accuracy of \pm $0.5^{\circ} \mathrm{C}$ and $\pm 5 \%$. Manual measurements were also made on the walls. 


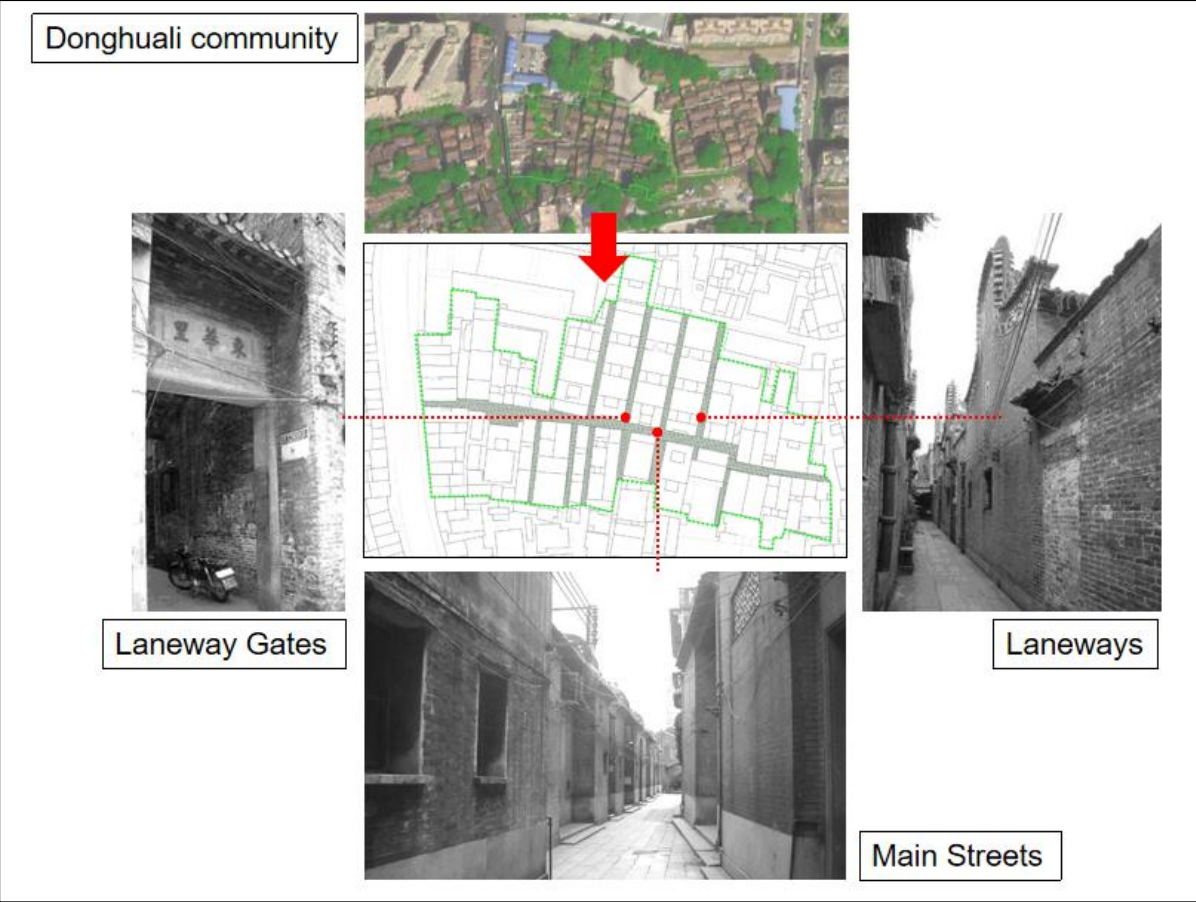

Figure 1. The traditional urban planning. Photo Source: Author's own painting.

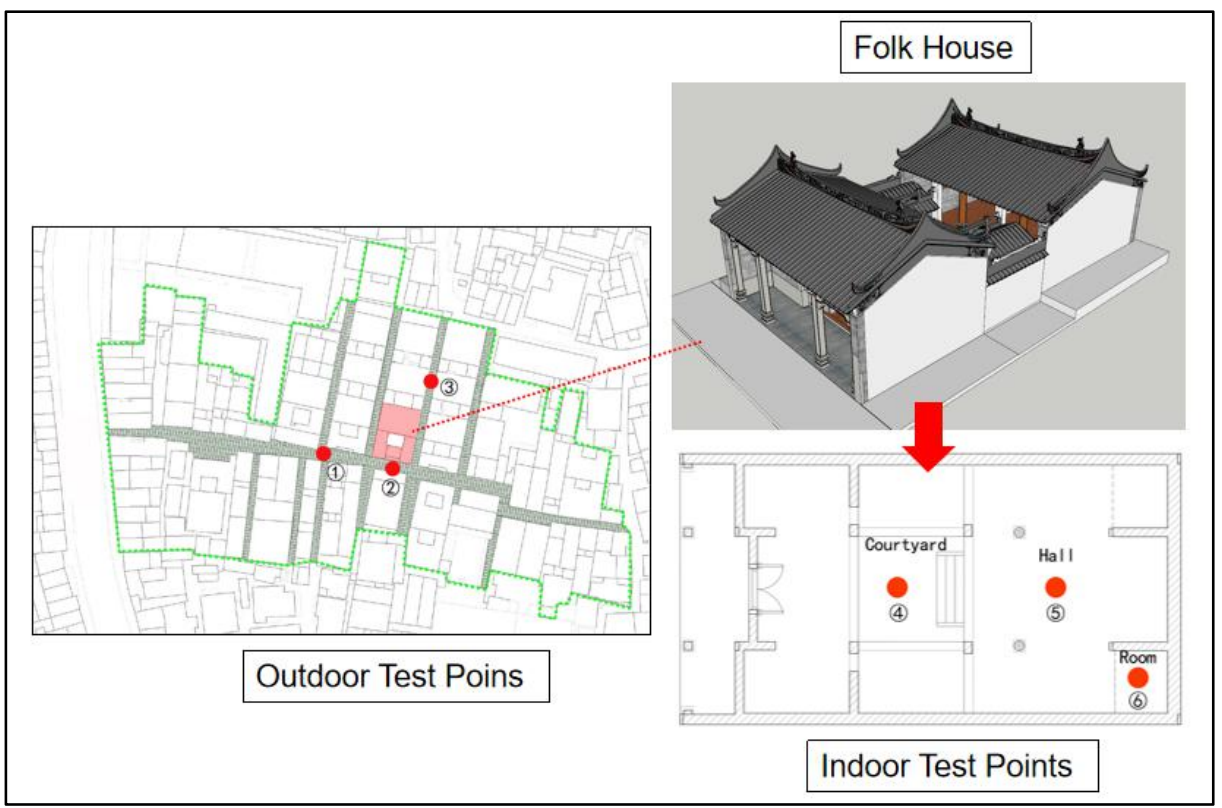

Figure 2. Measurement points of the thermal environment.Photo Source: Author's own painting.

\subsection{Use of the Paragraphs Air Temperature, Relative Humidity, Wind Speed Measurement}

The temperature measurement results showed that the maximum and average values of air temperature during the daytime decreased in the sequence of "outdoor open area-courtyard-hall-bedroom"(Fig.3), and the time when the air temperature reached the peak was also delayed in the above sequence. When the outdoor temperature reached $34.8^{\circ} \mathrm{C}$, the highest of the day, the temperature in the lobby of the residential house was $28.9^{\circ} \mathrm{C}$, a variation of $5.9^{\circ} \mathrm{C}$, and the the scale of temperature drop was $17 \%$. The temperature in the bedroom was only $28.1^{\circ} \mathrm{C}$, a difference of $6.7^{\circ} \mathrm{C}$, and the the scale of temperature drop was $19 \%$. The duration of the highest temperature in the lobby and the bedroom was delayed by $1.25 \mathrm{~h}$ and $2 \mathrm{~h}$ respectively compared with that in the open area. 
The results of air humidity measurement showed that the average relative humidity in residences during the daytime was $54 \%$, that at night $66 \%$, and the maximum $78 \%$ (Fig.4). The relative humidity indoors throughout the day was between $50 \%$ and $70 \%$ with a relatively concentrated range, accounting for $90.3 \%$. There showed a clear contrast in the outdoor relative humidity during the day and night.

The results of the wind speed measurement showed that its speed at night is almost $0 \mathrm{~m} / \mathrm{s}$ and that at the courtyard is almost $0 \mathrm{~m} / \mathrm{s}$ as well(Fig.5). However, as the outdoor temperature rose during the daytime, the temperature difference between indoor and outdoor gradually increased. The wind speed at the courtyard grew larger and fluctuated greatly in the range of variation $0 \sim 3.7 \mathrm{~m} / \mathrm{s}$. People generally could feel a slight breeze at this wind speed. At the same time, it could be seen that the outdoor wind speed had no characteristics and a minor impact on indoor wind speed. Due to the thermal pressure caused by the temperature difference between the main streets and the laneways during the day, the wind would flow from the laneways to the main streets.It can be concluded that the ventilation at the courtyard was mainly affected by the hot pressure ventilation. It was precisely because the ventilation of the courtyard took away the hot indoor air, which had a good cooling effect on the room. This is also an important reason that caused the indoor air temperature lower than the ambient temperature.

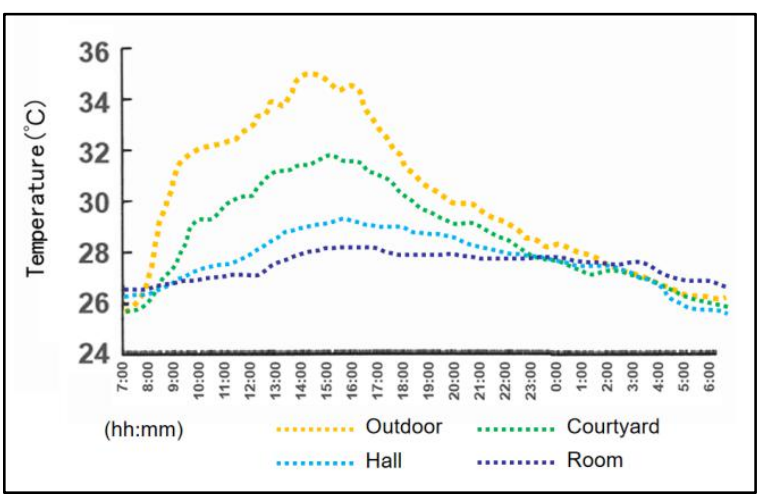

Figure 3.Temperature.Photo Source: Author's own painting.

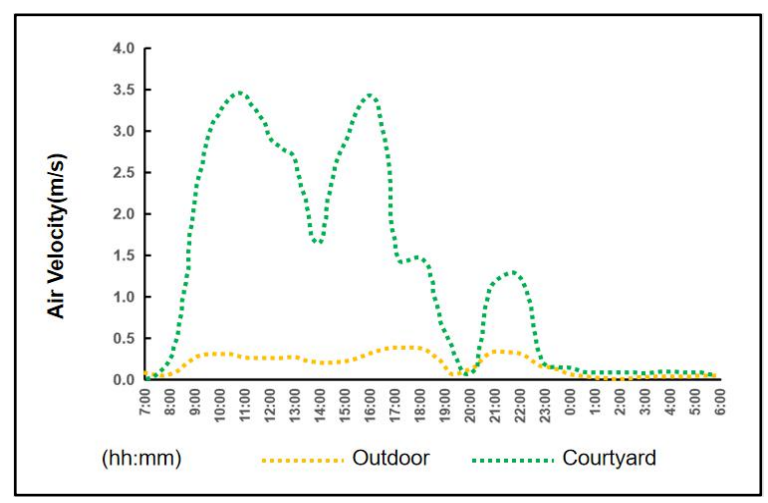

Figure 5.Air Velocity.Photo Source: Author's own painting

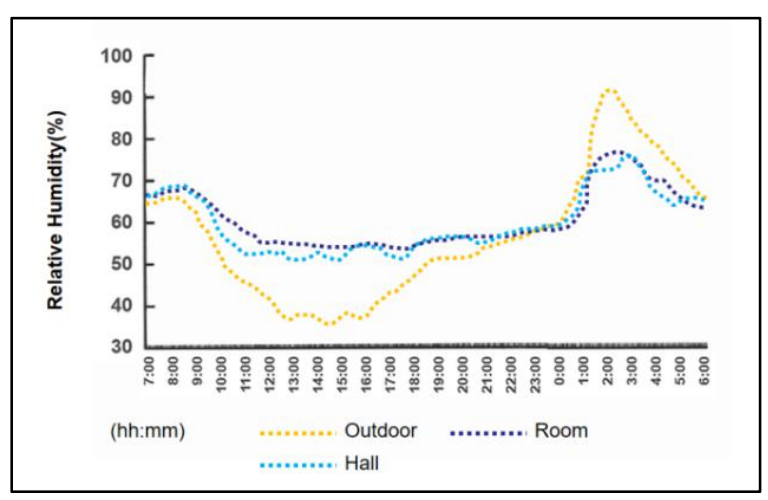

Figure 4.Relative Humidity.Photo Source: Author's own painting.

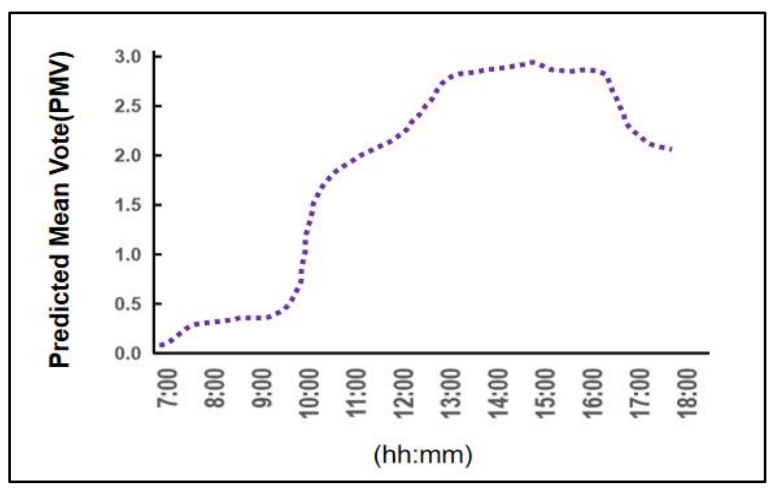

Figure 6.Predicted Mean Vote(PMV).Photo Source: Author's own painting

\subsection{Pmv Test Result Analysis}

ISO7730 is a widely used standard for evaluating and predicting indoor thermal comfort level in the world. It describes the PMV-PPD index proposed by Professor Fanger from Denmark to predict human thermal sensation(Dis, 1985). It could be seen from Figure 6 that the PMV is less than 2 before 10:30. During this period, residences could meet the thermal comfort requirements of human body without any measures. 
The time when PMV was greater than 2.8 accounted for about $30 \%$ of the total test time. In summer, it can reach such a value, which shows that the thermal comfort of residences is good. As long as some simple auxiliary equipment (such as electric fans) can meet the thermal comfort requirements of human body.

\section{Results and Discussion}

From this thermal environment measurement, it was found that the traditional community and residences in Lingnan, represented by Donghuali community, have special climate adaptability to the hot and humid environment. Through data analysis and sorting, we focused on conducting research on the layout of the community's streets and lanes, courtyard space, halls and indoor hollowed out partitions and pointed out that they are all effective means to ensure good "natural air conditioner" effects in indoor spaces.

\subsection{Street Layout}

The traditional residences in Lingnan are dominated by "comb layout". Roadways are parallel to the prevailing wind direction in summer. The wind pressure from the outside creates a smooth flow of air through the roadway, which is beneficial to take away the heat in the air. The average wind speed in the roadways on the test day was $1.2 \mathrm{~m} / \mathrm{s}$. The single residences are connected back and forth to achieve the effect of mutual shading. Local residents are used to calling them "cold lanes".The laneways connect all residential buildings in the overall layout of the community. When the airflow flows into the narrow laneways from the open main street, it cannot be accumulated in a large volume due to air quality, and then it accelerates to flow through the cold laneways, causing an increase in the wind speed, that is, the narrow tunnel effect. The mutual effects of main streets and laneways lead to the formation of an important ventilation pressure system for the external environment of the community(Fig.7、8).

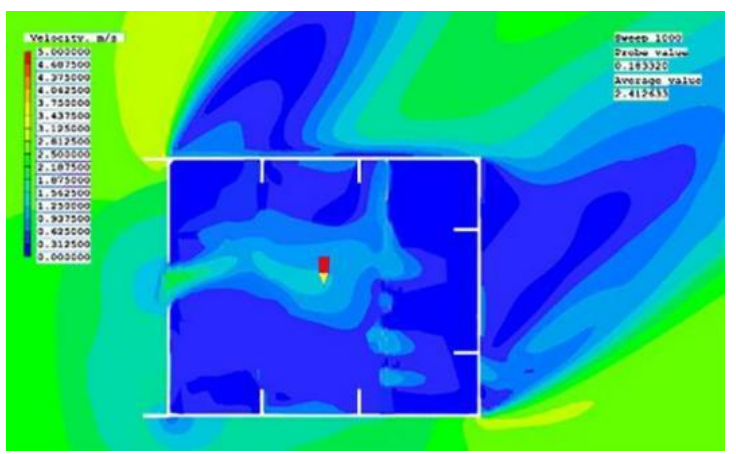

Figure 7.Ventilation simulation diagram.Photo Source: Author's own painting.

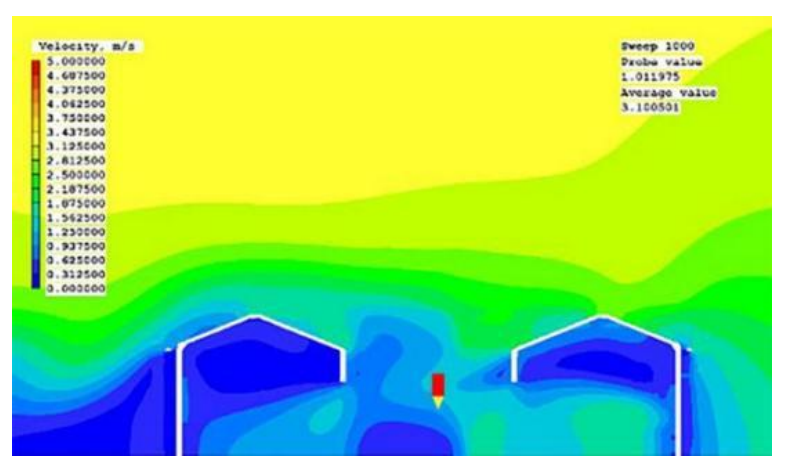

Figure 8.Ventilation simulation diagram.Photo Source: Author's own painting

\subsection{Courtyard Space}

Courtyard has multiple meanings and practical functions in traditional residential buildings, such as ethics, culture, family life, daily work, and microclimate adjustment(Fig.9). First of all, as a transitional space between the interior and the outside, the courtyard has an obvious thermal buffer effect. Taking this actual measurement as an example, the temperature in the courtyard during the daytime is always lower than outdoors, but higher than indoors. The semi-indoor property of the courtyard effectively buffers the outside temperature and stabilizes the indoor temperature. Secondly, the courtyard can generate heat and pressure ventilation inside the residence. Even in the period of no wind, since the temperature below the courtyard is lower than that above, the air has a rising pressure, causing the courtyard to produce 
weak air movement up and down, forming improved ventilation conditions. The joint effects of laneways and patios contribute to a suitable "thermal comfort" environment inside the building.

\subsection{Hollow out indoor partition}

In order to better utilize ventilation and convection to dissipate heat and moisture, various hollow out indoor partition methods are often used in the traditional constructions in Lingnan. For example, hollow doors and windows, screens, etc(Fig.10). are used to make air circulation more smooth, and partition walls are designed by folding and unfolding.

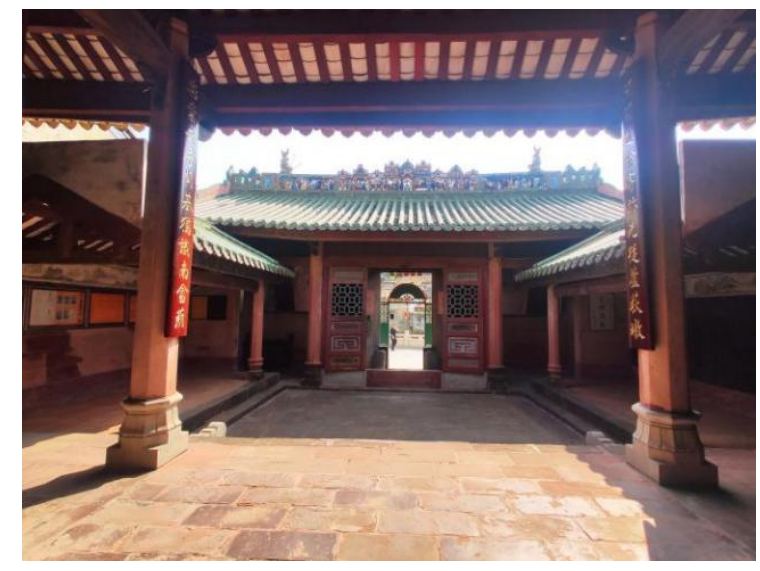

Figure 9.Courtyard ( Source:by author) .Source:by author

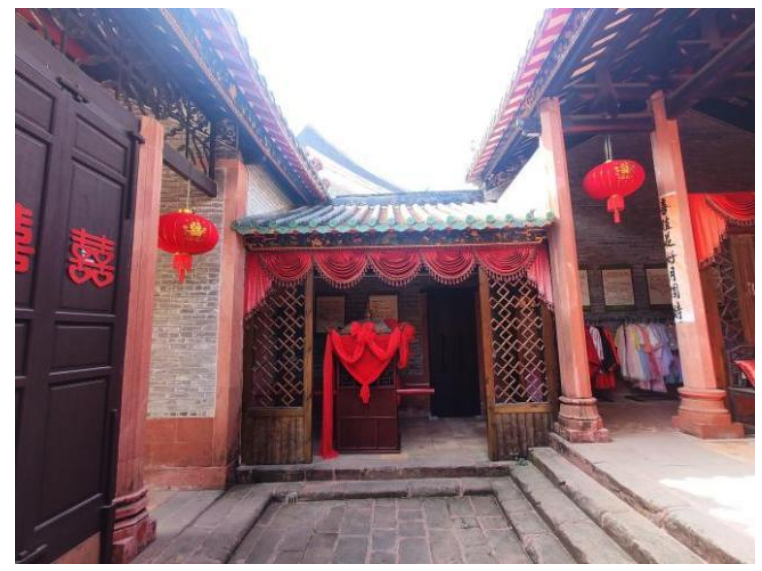

Figure 10.Hollow out Indoor Partition.Source:by author.

\subsection{Enlightenmen}

Traditional buildings emerged in those days without air-conditioning equipment. Regardless of the overall community planning and layout, building courtyard organization, ventilation system organization, or building interior, the principles of human comfort and energy conservation are followed. The wisdom of traditional building construction is mainly manifested in the ingenious balance of heat shielding, ventilation and natural lighting, facilitating nowadays architectural design to avoid the impact of adverse climatic elements. Through effective utilization of climatic resources and features, reduction of air conditioning energy consumption in summer, and less service time of air-conditioning in transition season, it can help directly convert into a practical method for building energy conservation. The traditional village planning in Lingnan area also manifests the traditional construction wisdom. It can be seen from the planning of Nanshe Village in Dongguan City that the residential building group is mainly in a "comb-like layout", where the lanes are parallel to the predominant wind direction in summer. The air flow formed under external wind pressure passes through the lanes smoothly, helping accelerate the air flow speed. On the other hand, a pond is built in the middle of the village by taking advantage of cooling effect of water. The lanes in the village are perpendicular to the pond, so that it can absorb the heat in the air to cool down(Fig.11). This method can provide reference for designers in modern urban planning to achieve double results with half the effort.

For example, the designer made use of the typical Lingnan climate and space, comprehensively adopted external sunshade layers, ventilating patios, three-dimensional courtyards and other spatial forms in the design of Guangzhou Nansha Development Power Building (2010). Located on the topography along the river at the mouth of the Pearl River, with the predominant wind direction from the eastward Pearl River, the project adopted corridor-patio layout and created good natural ventilation conditions. In the vertical space, a natural ventilated atrium with an open upper part was adopted for the natural lighting and ventilation inside; meanwhile, on different vertical faces, sky gardens are set up to create a good view of external landscape and ventilation opening. Therefore, a "layout of vertical patio + side courtyard" is 
established, which can effectively form a thermal buffer space and play a role of sun-shading and heat shielding(Xiao and Liu, 2015)(Fig.12).

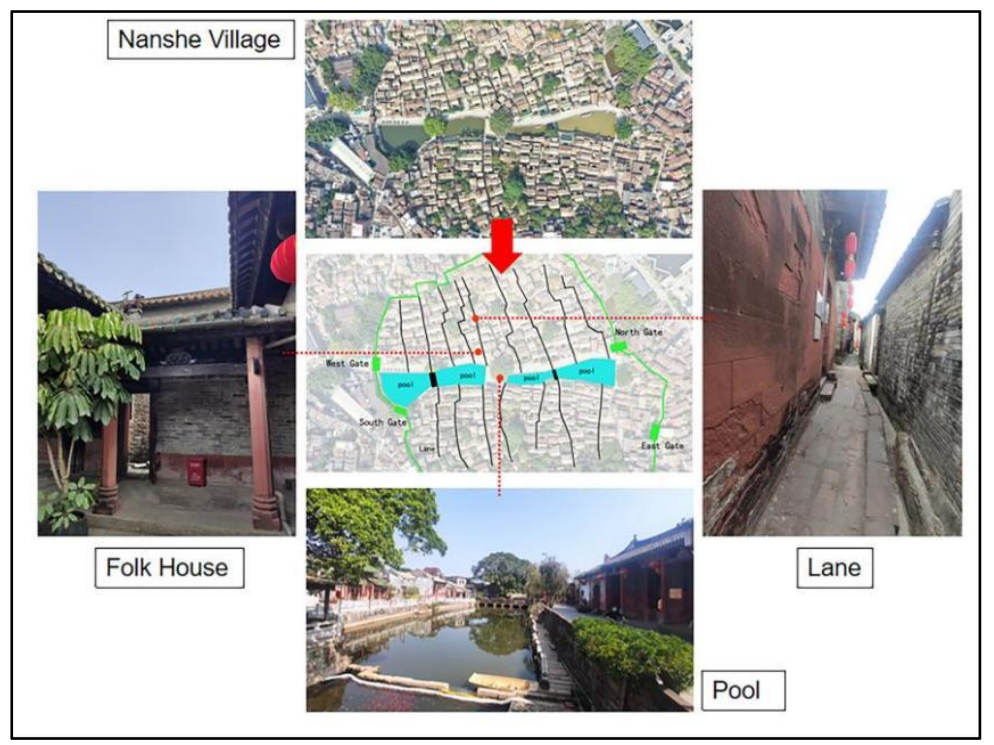

Figure 11.The traditional buildings adopts unique layout design techniques.Photo Source: Author's own painting.

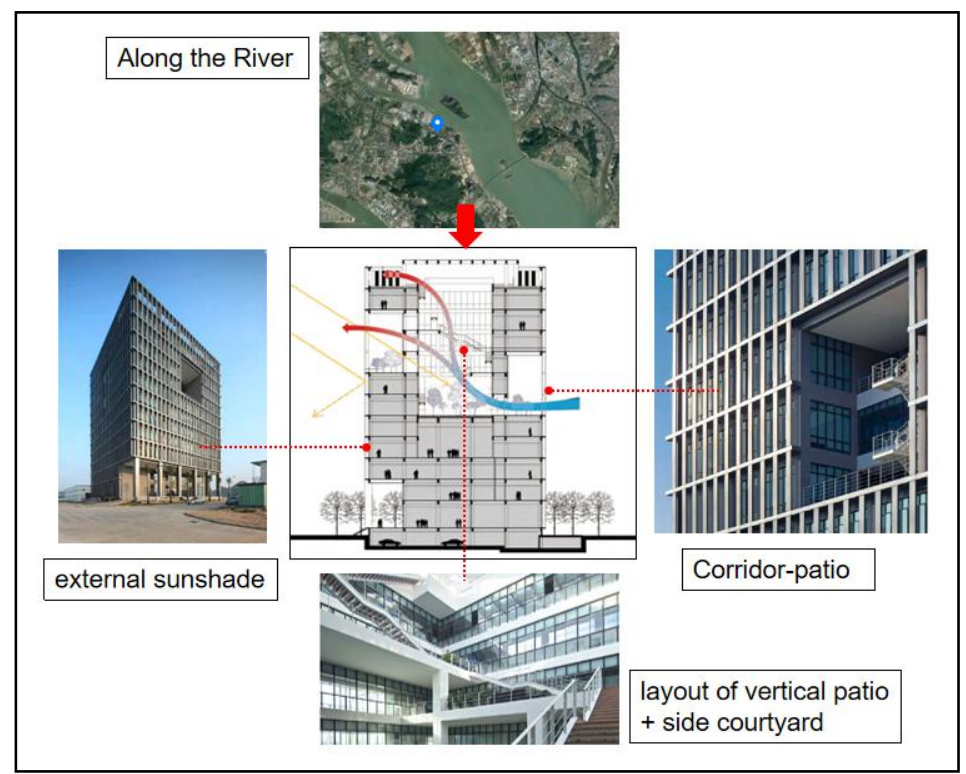

Figure 12.Urban planning application case diagram.Photo Source: Author's own painting.

\section{Conclusions}

The conclusion of this paper is that the construction wisdom of Lingnan traditional architecture can effectively solve the problem of hot and humid climate in summer in southern China without active energy sources assistance, better meet the requirements of the PMV, and play a positive role in the sustainable development of Urban planning in the post-epidemic era. The breakout of COVID-19 is not only a test for all mankind, but also a reflection on the healthy buildings. In the post-coronavirus era, architecture should not only stay in the temporary state of simply preventing the recurrence of the 
epidemic. The potential risks that the building may face should be analyzed more systematically to comprehensively improve the sustainable development of the building.

\section{References}

NiRiain C, Kolokotroni M.(2000), "Cooling Effectiveness of South Fa\&ccedil;ade Passive Stacks in a Naturally Ventilated Office Building", Indoor \& Built Environment, Vol. 8 No. 5, pp. 309-321.

Li B, Guo W, Dou J, Liu X, Zhang Y,(2021), 'Research on the diagnosis and treatment of thermal environment from the perspective of healthy building'.,Industrial Construction. https://doi.org/10.13204/j.gyjz G20103004

Allard, F., Santamouris, M., Mendez, S. \& James, N. (1998), "Natural ventilation in building: a design handbook".London: James and James Science Publishers Ltd

DIS, I. (1985), Moderate thermal environments: determination of the PMV and PPD indices and specification of the conditions for thermal comfort, [S]. Geneva:Internation Standard Organization, 1984.

Fan, W. , Guo, C. , \& Wang, X. . (2009), "State of the art and Discussion of Natural Ventilation Technology", Contamination Control \& Air-Conditioning Technology,,(2):5- 10.

Xiao, Y. , and Liu .S. (2015) 'A study on the scale of LingNan traditional architectural climate space'.Ecocity and Green Building,(2):73- 79

Zhao P, Hui S .(2005).' Influence Factors and Implementation of Natural Ventilation'.IDEA\& PRACTICE OF DESIGN,(5):54- 56. 